\title{
Rural-led Exchange Rate Appreciation in China*
}

\author{
Gordon Menzies \\ University of Technology, Sydney \\ Peter Dixon \\ Victoria University \\ Xiujian Peng \\ Victoria University \\ Sylvia Xiaolin Xiao ${ }^{\dagger}$ \\ UW - Madison \\ Maureen Rimmer \\ Victoria University
}

January 30, 2016

\begin{abstract}
The departure of a factor in excess supply in a non-traded rural sector leads to a Rural-led Exchange Rate Real Appreciation (RERA), in a dual economy setup. The RERA highlights for the first time a potential link between intra-national factor movements and real exchange rates. In China, where there is excess labour employed in the production of (largely) nontraded rural goods, we attribute around one third of the recent appreciation of the real exchange rate - defined as the relative price of nontradables to a RERA effect.
\end{abstract}

JEL classification: F11, F31, F43

Key words: Exchange Rates, Dual economy, Balassa-Samuelson Effect, China

*The authors would like to thank Rabah Amir, Leon Berkelmans, Adam Cagliarini, Mei Dong, Taya Dumrongrittikul, Susumu Imai, Mario Fiorini, Adrian Lee, Elizabeth Savage Frances Stewart, David Vines, John Wooders and seminar participants at 2012 Australian Conference of Economists and University of Technoloy, Sydney, for valuable suggestions and comments on our draft paper. We also acknowledge the assistance work of Yinhua Mai. And Xiao acknowledges the funding support from Dan Searle Fellowships since August, 2015.

${ }^{\dagger}$ Corresponding author: Department of Economics, University of Wisconsin-Madison; Email: xxiao37@wisc.edu. 


\section{Introduction}

This paper aims to build a dual-economy model to show how China's structural transformation affects its real exchange rate. As the 2nd largest economy by GDP, but still a dual economy, China's structure transformation and exchange rate movement matter considerably to the world economy. Since China opened up its economy in 1978, its rapid growth has been accompanied by ongoing institutional reform and structure changes, including labor market and exchange rate regimes.

In this paper, we argue that a simple modification to a dual-economy model of intra-national labour movements predicts a real exchange rate appreciation what we call a Rural-led Exchange Rate Appreciation (RERA). Our modification is to assume that the rural sector is dominated by the production of non-traded output (nontradables), and the urban sector is dominated by the production of traded output (tradables). The RERA prediction draws together a number of different strands of literature as follows.

\subsection{Agricultural Surplus Labour and Growth}

Papers descending from Lewis (1954) and Jorgenson (1961) have focused on the growth transition of developing countries. As a reaction to perceived limitations of single sector models of growth, and in keeping with the high negative correlation between economic development and agriculture's share of GDP (Vollrath, 2009), these scholars proposed that the relationship between the agricultural and manufacturing sectors was a key determinant of the growth trajectory.

"... [A model with only one producing sector] rules out much of what is interesting about growth and development, at least if the empirical and institutional literature is any guide. A few examples of 'special situations' or 'unsolved problems' created by concentration on a single output or a single production relation are: balance between industries in economic growth, imbalance between advanced and backward countries in international trade and the development of 
a dual economy, that is, of an economy with an advanced or modern sector and a backward sector as well." (Jorgenson, 1961, pg 310)

Various configurations of the "advanced" and "backward" sectors have been proposed under what has been called the "Lewis model" (Lewis, 1954), with key modelling choices relating to the technologies and institutions of the sectors, and to the behaviors of individuals contemplating migration to the city (Ranis and Fei, 1961, Fei and Ranis, 1964, Harris and Todaro, 1970). ${ }^{1}$

An example of a recent paper in this strand of literature is Hayashi and Prescott (2008). They argue that pre war Japanese primogeniture restrained Lewis-style rural emigration and held back economic growth. In support of their modelling setup, which clearly violates the application of the equal-marginal principle to labour, they cite recent papers in the field of Development Accounting which suggests that in many countries the allocation of labour and capital is inefficient, evidenced by the fact that their marginal products are not equated across sectors. $^{2}$

Vollrath (2009) in particular has made a compelling case that such inefficiencies exist between rural and urban labour allocations in many countries. Table 1 lists estimates of the ratio of the marginal products of labour in the industrial sector to the marginal product of labour in agriculture. As a cross-check Vollrath collected any available data on the ratio of industrial wages to rural wages, and found a correlation of $0.81(P<0.01)$. The Table is suggestive of higher misallocation in non-OECD countries, which generalizes Hayashi and Prescott's story

\footnotetext{
${ }^{1}$ Rural-urban migration is the defining mechanism in Lewis (1954). The migration is due to the accumulation of urban capital, given a constant socially-determined wage in the rural sector. The papers by Fei and Ranis describe in detail how rural labour market conditions evolve when the socially determined wage is abandoned, and finally begins to rise at the so called Lewis turning point. Thereafter the relationship of the rural wage becomes more closely aligned to the marginal product and the economic development dynamic draws to a close. Harris and Todaro (1970) explain persistent urban-rural wage differential by an employment lottery. Some rural workers, faced with a choice between a certain rural wage and an uncertain urban wage, hesitate which allows a wage premium to remain in place for urban jobs.

${ }^{2}$ See Caselli (2005) for a literature review and Restuccia et al. (2008) for a recent dualeconomy productivity model.
} 
that development involves the removal of these misallocations. ${ }^{3}$

Table 1: Ratio of Industrial MPL to Rural MPL

(highest to lowest, OECD bold)

\begin{tabular}{|lr|lr|ll|}
\hline Kenya & 16.84 & Venezuela & 3.86 & Sth. Korea & 2.65 \\
Malawi & 13.72 & Guatemala & 3.78 & China & 2.57 \\
Zimbabwe & 11.91 & Iran & 3.70 & France & 2.41 \\
Sth Africa & 9.37 & Norway & 3.37 & Finland & 2.32 \\
Peru & 7.44 & Indonesia & 3.32 & US & 2.26 \\
Honduras & 6.26 & Japan & 3.31 & Chile & 2.10 \\
Portugal & 5.21 & India & 3.21 & Netherlands & 2.05 \\
Pakistan & 4.70 & Turkey & 3.03 & Colombia & 2.03 \\
Egypt & 4.55 & Greece & 2.91 & Canada & 2.00 \\
El Salvador & 4.53 & Denmark & 2.90 & UK & 1.89 \\
Austria & 4.27 & Tunisia & 2.88 & New Zealand & 1.83 \\
Costa Rica & 4.23 & Argentina & 2.81 & Uruguay & 1.81 \\
Philippines & 3.91 & Sri Lanka & 2.73 & Syria & 1.74 \\
Italy & 3.89 & Sweden & 2.70 & Australia & 1.67 \\
\hline
\end{tabular}

Source: China from Mai et al. (2014). All other countries from Vollrath (2009) pg. 330 , Table 2

Drawing on Table 1, our own dual-economy configuration of the 'advanced' and 'backward' sectors stipulates an exogenous barrier that prevents labour mobility to the city. As an example, we will focus on the rural-urban migration of labour in China. We posit that the Household Registration (or hukou) system in China stops the ratio of marginal products falling, and, stems the flow of rural workers to cities, much as primogeniture did in the setup of Hayashi and Prescott $(2008){ }^{4}$

\footnotetext{
${ }^{3}$ The non-OECD mean (5.3) is significantly higher than in the OECD (2.8) in a t-test with unequal variances $(\mathrm{P}=0.0055)$.

${ }^{4}$ Hukou system has been a central instrument of the command economy since its inception in 1958, to prevent "undesirable" rural-to-urban migratory flows (Chan, 2010). The regulation decreed that all internal migrating be subject to approval by the relevant local government.
} 


\subsection{Surplus Labour often Produces Nontradables}

We take as an implication of the 'food problem' literature (Schultz, 1953) that many developing countries have excess workers in subsistence agriculture producing food, which is nontraded by definition. Gollin et al. (2004) make this case, drawing on the UN Food and Agriculture Organization (FAO) data. In all developing countries, agriculture employs 55 per cent of workers, and in the 65 poorest of these, the share is closer to 60 per cent. For a number of countries (including Rwanda, Burundi, Burkina Faso and Nepal) over 90 per cent of workers are in agriculture. As to what the rural workers produce:

"Some agriculture is devoted to producing non-food crops and export crops, which might challenge our underlying assumption that the agriculture sector essentially produces food for domestic consumption. But it turns out that in most poor countries, agricultural land and labor are overwhelmingly devoted to food production - and specifically, to meeting the subsistence needs of the population. For example, FAO reports that in 2000, 68.6 percent of arable land in 159 developing countries was devoted to staple food crops: grains, pulses (beans, peas, lentils, etc.), roots and tubers..." (Gollin et al., 2004, pg. 7)

One could debate the status of China as a developing country and hence the relevance of this quote, were it not for the fact that there is compelling and independent evidence that rural output is indeed nontraded in that economy. In Dumrongrittikul (2012), the rural sector of China is classified as non-traded. That is, the average of the import and export share is less than $10 \%$, the generally accepted cutoff (De Gregorio et al., 1994).

Each person has a Hukou, classified as "rural" or "urban", in a specific administrative unit. Hukou system limited the rural-urban labor mobility and also excluded rural population from access to state-provided goods, welfare, and entitlements. Since 1978, China has relaxed Hukou system, particularly in small and medium-size cities. However, in general, Hukou system still matters considerably in big cities and prevents free labour mobility between rural and urban sectors. 


\subsection{Balassa-Samuelson Effect and China's Exchange Rate}

In another literature, dual economies appear as a modelling device in open economy macroeconomics and international trade theory. Within this literature there is cluster of existing ideas invoked to explain what is usually called the BalassaSamuelson effect (Balassa, 1964, Samuelson, 1964). ${ }^{5}$ This is the phenomenon whereby countries with higher productivity in tradables compared with nontradables have higher price levels of nontradables in terms of tradables. It has remained a robust finding over many decades, as can be seen in Kravis, Heston and Summers (1978, 1983), De Gregorio et al. (1994), Canzoneri et al. (1999), Lane and Milesi-Ferretti (2002), Kakkar (2003) and more recently in Cardi and Restout (2015). The latter is germane to our modeling. They revise the BalassaSamuelson model by considering imperfect labor mobility across sectors and physical capital accumulation. This relates to our model since the wages across sectors do not equalize as in Table 1. However, the imperfect labor mobility in Cardi and Restout (2015) comes from the imperfect substitutability in hours worked across sectors, while, in our paper, we highlight the institutional barrier of labor mobility across sectors, i.e, Hukou system in China.

In the case of China specifically, there are a number of recent papers which attempt to explain exchange rate movements using the Balassa-Samuelson hypothesis, as surveyed by Zhang (2012). They include Lin (2007), Lu and Liu (2007), Tang and Qian (2007), Wang and Yao (2009), Guo (2010), Tyers and Zhang (2011) and $\mathrm{Hu}$ and $\mathrm{Su}$ (2013). The evidence is mixed: vindication is claimed in Guo (2010), Lu and Liu (2007), Tang and Qian (2007) and BalassaSamuelson is found wanting in Lin (2007), Tyers and Zhang (2011) and Wang and Yao (2009). The latter articles point to the evolution of exchange-rate and

\footnotetext{
${ }^{5}$ Samuelson himself, in a self-effacing moment (Samuelson, 1994), calls it the Penn effect (Milton and Kravis, 1954). He suggests a fair title would be a Ricardo-Viner-Harrod-BalassaSamuelson-Penn-Bhagwati-et al. effect, while Obstfeld and Rogoff (1996) opt for HarrodBalassa-Samuelson with a footnote acknowledgement of Ricardo.
} 
trade regimes since the liberalization following 1978, and to the reality of the dual economy which, they claim makes the theory implausible. In fact, even some supportive papers, such as Lu and Liu (2007), and, Hu and Su (2013) warn about these 'Chinese characteristics' which should be taken into account when interpreting their conclusions.

The relationship between Balassa-Samuelson effect and those 'Chinese characteristics' motivates our paper. Our main contribution is to show how the tradablenontradable dichotomy of Balassa-Samuelson model can form the backdrop to a dual-economy setup created by an institutional friction. Then, we show how both tradables productivity improvement and removal of an institutional labor market friction can appreciate the real exchange rate. We show this in theory (section 2) and in historical calibration (section 3).

The macroeconomic and trade results in the Balassa-Samuelson literature have often be expressed in a comparative static form, though they can also be built into growth models (see Obstfeld and Rogoff, 1996, Chapter 4). We present comparative static results in our paper, focussing on the real exchange rate - a key variable of interest within the international trade and macroeconomics literature - measured as the relative price of nontradables in terms of tradables.

The rest of the paper is organized as follows: in Section 2, we describe the environment, present our model and then discuss its affinity with, and difference from, the Balassa-Samuelson model; in Section 3, we do the input-output CGE (computable general equilibrium) simulation, based on the model; and we conclude in Section 4.

\section{RERA Model}

In this section we describe the modeling environment in Section 2.1, and then formally connect a Lewis-style labour movement due to the removal of a restriction to the Balassa-Samuelson effect in Section 2.2. This provides the analytic tools to 
compare and contrast the RERA and Balassa-Samuelson real appreciations, and a secondary task is to examine other drivers of exchange rates and rural labour

which become important in our calibration exercise (Section 3). In Section 2.3 we compare and contrast the two graphically. For expositional ease, the model in the main text is developed using simple Cobb-Douglas functional forms, but we also solve it for general linear homogenous production and preferences in Appendix.

\section{$2.1 \quad$ Environment}

Consider a small open economy in which there are two sectors producing tradables $(T)$ and nontradables $(N)$, as in the model of Section 4.2.1 of Obstfeld and Rogoff (1996). Competitive firms maximize profits, taking factor input prices as given. In an extension of their setup, all tradables are produced in urban areas and all nontradables are produced in rural areas. Labor is internationally immobile and can migrate between the two sectors, but there is some institutional barrier to prevent free mobility from rural to urban areas. The total labor supply is $L=L_{T}+L_{N}$, and we can normalize $L \equiv 1$. Furthermore, the institutional barrier makes labor allocations $L_{T}$ and $L_{N}$ depart from single labor market optimal allocations $L_{T}^{*}$ and $L_{N}^{*}$, such that $L_{T} / L_{N}=\psi L_{T}^{*} / L_{N}^{*}$, where $\psi \in(0,1]$. That is, too much labor is allocated to nontradables in rural areas and, as a consequence (not as an assumption), the same discount factor applies in equilibrium to wages paid in the production of nontradables: $w_{N}=\psi w_{T}$, as we shall show in the model. In a non-optimal solution the two labor markets are segmented but clearly the departure from optimality is decreasing in $\psi$ with the distortion disappearing entirely at the upper limit of $\psi$. So any increase in $\psi$ towards unity may be thought of as a liberalization of labor movements towards the optimal allocations of labour.

Capital is put in place a period before it is actually used, and the world rate of return for capital is $r$. Following Obstfeld and Rogoff (1996), it does not matter 
if capital is accumulated by individuals and allocated through a rental market or is accumulated by firms for their own use. The RERA and Balassa-Samuelson exchange rate results are unrelated to the ownership of capital, so without loss of generality we assume that consumers only receive labor income in the next section. Production technology in Sector $j$ is a constant-returns Cobb-Douglas function, $Y_{j}=A_{j} K_{j}^{\alpha_{j}} L_{j}^{1-\alpha_{j}}$, where $j=\{T, N\}, A_{j}$ is the total factor production parameter, $K_{j}$ is capital input, and $L_{j}$ is labor input, with $\alpha_{j}$ being the output elasticities of capital.

The tradable and nontradable sectors of this economy produce the only two types of goods consumed: tradables and nontradables. Tradable goods can be shipped between countries free of taxes or transport costs, with the price level $P_{T}$, while nontradables are so costly to ship that they never leave the country where they are produced, with the price level $P_{N}$. We normalize $P_{T} \equiv 1$ so that the relative price of nontradables to tradables is, $p=P_{N} / P_{T}=P_{N}$. The real exchange rate in our paper is the relative price of nontradables to tradables, as is standard in the Balassa-Samuelson literature.

The relationship between this measure of the real exchange rate and the other conventional measure of the real exchange rate, namely relative CPIs in the same currency, turns out to be important in our calibrations of Section 3. Let $s$ be the nominal exchange rate such that an increase in $s$ is an appreciation. The real relative CPI exchange rate is $s p / p^{f}$, where $p$ and $p^{f}$ are the local and foreign price levels. Let both $p$ and $p^{f}$ be a Cobb-Douglas price index: $p=P_{T}^{\omega} P_{N}^{1-\omega}$ and $p^{f}=\left(P_{T}^{f}\right)^{\omega}\left(P_{N}^{f}\right)^{1-\omega}$. Suppose the Law of One Price holds for traded goods, i.e. $s P_{T} / P_{T}^{f}=1$. It then follows that $s p / p^{f}=\left[\left(P_{N} / P_{T}\right) /\left(P_{N}^{f} / P_{T}^{f}\right)\right]^{1-\omega}$. If foreign prices are fixed, they can be normalized alongside $P_{T}$, establishing the one to one correspondence between the nontradable price and the relative CPI real exchange rate. For simplicity, the exponent in the last expression is often ignored when discussing real exchange rates. Therefore, in our model we follow 
the convention that the real exchange rate is the relative price, $p=P_{N}$. If the law of one price does not hold, $s P_{T} / P_{T}^{f}$ is a positive function of $s$. In that case, the relative CPI measure of the exchange rate is more volatile than the relative price of nontradables, which proves to be so in our calibrations. In addition, a hat on any variable or parameter denotes proportional change. For example, $\hat{p}$ is the proportional change on the real exchange rate, $p$.

We suppose there is a representative agent in the economy, with preferences $U=C_{N}^{\theta} C_{T}^{1-\theta}$, where $C_{N}, C_{T}$ are the consumption of nontradables and tradables, and $\theta$ is the utility elasticity of nontradable consumption. The problem for this representative agent is to maximize utility subject to an income constraint. As flagged earlier, all income for the representative agent is labour income. We solve the model in two steps. Firstly, it is solved without any labour restriction $(\psi=1)$ to obtain optimal labour allocations. Then we put in a labour constraint relative to the optimal solutions $(\psi<1)$ and show that the wage discount is the inverse of the labour ratio discount - that is, $10 \%$ too much labour in $N$ leads to a $10 \%$ wage discount on workers in $N$. For simplicity, we focus on the steady state equilibrium of the model, not the dynamics.

The equilibrium is defined by zero net demand for nontradables with the equilibrating mechanism being a flexible price of nontradables. Wages are flexible within the segmented labour markets, in the non optimal solution. And wages paid in tradables production are the same as that paid in nontradables in the optimal solution, when there is a single labour market. 


\section{$2.2 \quad$ Model}

In the economy, the production functions for the tradable and nontradable sector are as follows,

$$
\begin{gathered}
Y_{T}=A_{T} K_{T}^{\alpha_{T}} L_{T}^{1-\alpha_{T}} \\
Y_{N}=A_{N} K_{N}^{\alpha_{N}} L_{N}^{1-\alpha_{N}} .
\end{gathered}
$$

We normalize the labor supply to unity,

$$
L_{T}+L_{N}=1
$$

Profit maximization occurs by setting marginal products of capital ( $M P K$ ) and labor $(M P L)$ in two sectors equal to firms' costs to hire them,

$$
\begin{gathered}
M P K_{T}=r, \\
p \cdot M P K_{N}=r, \\
M P L_{T}=w_{T}, \\
p \cdot M P L_{N}=w_{N} .
\end{gathered}
$$

For a representative agent, the utility function is,

$$
U=C_{N}^{\theta} C_{T}^{1-\theta}
$$

by which we can derive, $C_{N}=\theta\left(w_{T} L_{T}+w_{N} L_{N}\right) / p$, and $C_{T}=(1-\theta)\left(w_{T} L_{T}+\right.$ $\left.w_{N} L_{N}\right)$. That is, nontradable consumption is a share $\theta$ of total labor income while tradable consumption is a share $(1-\theta)$ of total labor income.

Firstly, we consider a single labor market, in which labor can migrate freely between sectors within the economy. And we can get an optimal solution from this setting. Equation (4) and differentiation of (1) gives the tradables capital- 
labour ratio which is then substituted into (6) to obtain the economy-wide wage,

$$
w_{T}=A_{T}\left(1-\alpha_{T}\right)\left(\frac{\alpha_{T} A_{T}}{r}\right)^{\alpha_{T} /\left(1-\alpha_{T}\right)}=w_{N}=w
$$

Similarly, (5) gives the nontradables capital-labour ratio which is then substitutes into (7) to obtain a similar expression to (9) but with an endogenous $p$. This is then equated to (9) because wages are equalized in a single labor market and solved for $p^{*}$, our measure of the real exchange rate in optimality,

$$
p^{*}=\frac{A_{T}^{\left(1-\alpha_{N}\right) /\left(1-\alpha_{T}\right)} r^{\left(\alpha_{N}-\alpha_{T}\right) /\left(1-\alpha_{T}\right)}}{A_{N}}\left[\frac{\left(1-\alpha_{T}\right) \alpha_{T}^{\alpha_{T} /\left(1-\alpha_{T}\right)}}{\left(1-\alpha_{N}\right) \alpha_{N}^{\alpha_{N} /\left(1-\alpha_{N}\right)}}\right]^{1-\alpha_{N}}
$$

As noted earlier, the representative consumer apportions labor income over the two goods. Using demands derived from (8), the definition of nontradables as $C_{N}=Y_{N}$ and the fact that $w L_{N}=p\left(1-\alpha_{N}\right) Y_{N}$, we have,

$$
\begin{gathered}
p Y_{N}=\theta\left(w L_{N}+w L_{T}\right)=\theta w \\
\rightarrow \quad \frac{w L_{N}}{1-\alpha_{N}}=\theta w \\
\rightarrow \quad L_{N}^{*}=\theta\left(1-\alpha_{N}\right), L_{T}^{*}=1-L_{N}^{*},
\end{gathered}
$$

where $L_{N}^{*}$ and $L_{T}^{*}$ is the optimal labor allocation.

Then we solve with a segmented labour market, where there is too much labour in $\mathrm{N}$ such that,

$$
\frac{L_{T}}{L_{N}}=\psi \frac{L_{T}^{*}}{L_{N}^{*}}, 0<\psi \leq 1
$$

Using demands derived from (8), and noting that wages $w_{N}$ and $w_{T}$ cannot equalize to an economy-wide $w$ if there is a labour restriction away from optimality, 
we have,

$$
\frac{w_{N} L_{N}}{w_{T} L_{T}}=\theta\left(1-\alpha_{N}\right)\left[\frac{w_{N} L_{N}}{w_{T} L_{T}}+1\right]
$$

Substituting in (12) and rearranging we obtain $w_{N} / w_{T}=\psi$. That is, as flagged in the first paragraph of $2.1,10 \%$ too much labour in $N$ leads to a wage discount on workers in $N$ of $10 \%$. It remains to work out the effect of this distortion on the real exchange rate. By $w_{T}$ and $w_{N}$ from (6) and (7) and the ratio $w_{N} / w_{T}=\psi$, we have,

$$
p=\psi^{1-\alpha_{N}} \frac{A_{T}^{\left(1-\alpha_{N}\right) /\left(1-\alpha_{T}\right)} r^{\left(\alpha_{N}-\alpha_{T}\right) /\left(1-\alpha_{T}\right)}}{A_{N}}\left[\frac{\left(1-\alpha_{T}\right) \alpha_{T}^{\alpha_{T} /\left(1-\alpha_{T}\right)}}{\left(1-\alpha_{N}\right) \alpha_{N}^{\alpha_{N} /\left(1-\alpha_{N}\right)}}\right]^{1-\alpha_{N}} .
$$

Comparing (10) with (13), we can see when $\psi=1, p=p^{*}$.

Equation (13) is the key interpretive tool of our model, and its log differentiation provides all the required elasticities. The removal of a labour restriction, whereby there is too much labour in nontradables, and as a result wages are too low, can be modelled as a comparative static increase in $\psi$ in (13). From (13), we have $\hat{p}=\left(1-\alpha_{N}\right) \hat{\psi}$; and from (12) in the neighborhood of $L_{N}=0.5$ with given $L_{N}^{*}$ and $L_{T}^{*}$, we have $\hat{L}_{N}=-\hat{\psi} / 2$. Since wage rates in tradables don't change $\left(\hat{w}_{T}=0\right.$, since $(9)$ doesn't involve $\left.\psi\right)$, then we have, $\hat{w}_{N}=\hat{\psi}$, which can also be confirmed using $(7)$ and $\hat{p}=\left(1-\alpha_{N}\right) \hat{\psi}$.

We can now see clearly that the RERA and the Balassa-Samuelson effect are similar with regards to the real exchange rate. A classic Balassa-Samuelson effect is read off (13) by considering a rise in $A_{T}$ relative to $A_{N}$. For simplicity, suppose the latter is zero and we have $\hat{p}=\left(1-\alpha_{N}\right) \hat{A}_{T} /\left(1-\alpha_{T}\right), \hat{L}_{N}=0$; and if $w_{N} / w_{T}=\psi$ is unchanged, $\hat{w}_{N}=\hat{w}_{T}=\hat{A}_{T} /\left(1-\alpha_{T}\right)$ from the first equality in (9) which defines $w_{T}$ in a segmented labor market. As noted previously, we have $\hat{p}=\left(1-\alpha_{N}\right) \hat{\psi}$ in a RERA. Hence, in both cases (namely, $\hat{\psi}>0$ and $\hat{A}_{T}>0$ ), there is a real appreciation.

We also note that a decline in the utility taste for food, which is an outcome 
of economic development (Gollin et al. 2004) could be modelled by a decline in $\theta$. Were this to occur, changes in the equilibrium allocations of labour in (12) would drive changes to the actual allocations without any changes in prices or wages. That is, $\hat{p}=\hat{w}_{N}=\hat{w}_{T}=0$ since these variables are not affected by $\theta$ and $\hat{L}_{N}=\hat{\theta}\left(L_{T} / L_{T}^{*}\right)$.

We can now draw together the threads of our modelling in the form of four observations, which are germane for Section 3 as we try to explain recent movements of the Chinese real exchange rate.

(a) Firstly, a classic Balassa-Samuelson effect can explain an appreciation in (13) but in this model it does not lead to a labour movement because (11) does not contain $A_{T}$.

(b) Secondly, a RERA can explain an appreciation in (13), but it will lead to a Lewis-style labour movement as workers move to the city to pursue higher wages. As $\psi$ rises in (12), labour moves to the city.

(c) Thirdly, it is possible for both effects to occur together, or for a BalassaSamuelson effect to occur with an inefficient allocation of labour. This follows from $(13)$ where it is not necessary to set $\psi=1$ to model a Balassa-Samuelson effect.

(d) Finally, a decline in the utility taste for food will lead to labour emigration to the city, without any changes to the real exchange rate, prices or wages.

\subsection{Affinity between RERA and Balassa-Samuelson Ef- fect}

We have compared the RERA removal of a labor market imperfection to a Balassa-Samuelson effect using (13). We now compare them using Figure 1. In order to draw a simple diagram like this, it is helpful to fix the capital stock and transfer its ownership to domestic residents. ${ }^{6}$ On the left panel, we demon-

\footnotetext{
${ }^{6}$ The graphical advantage of this is that the total vaule of production becomes the income to factors, from Euler's Theorem, so that the budget set is defined by the tangency to the
} 
strate the RERA while on the right panel, we demonstrate a Balassa-Samuelson effect. As above, the price of tradables is the real exchange rate, $P_{N}$. In both cases, supply of nontradables (read as the production point $P$ projected onto the bottom axis) falls as a result of, respectively, a reallocation of labour as a distortion is removed and an increase in tradables' productivity. In both panels, the economy expands and with it the demand for nontradables (read as the consumption point $C$ projected onto the bottom axis). In the final equilibrium (not shown) the resultant gap between demand and supply of nontradables must be resolved by an increase in $P_{N}-$ a real appreciation. In the right panel, a classic Balassa-Samuelson improvement in tradable productivity leads to more of all goods demanded at $C$, while Rybczynski (1955) implies production at point $P$, again requiring a real appreciation (not shown).

Thus Figure 1 bears out the insight of (13) that the Balassa-Samuelson effect has a close affinity with the RERA. In both panels, $A$ is the initial point.

Figure 1: Rural-led Exchange Rate Appreciation

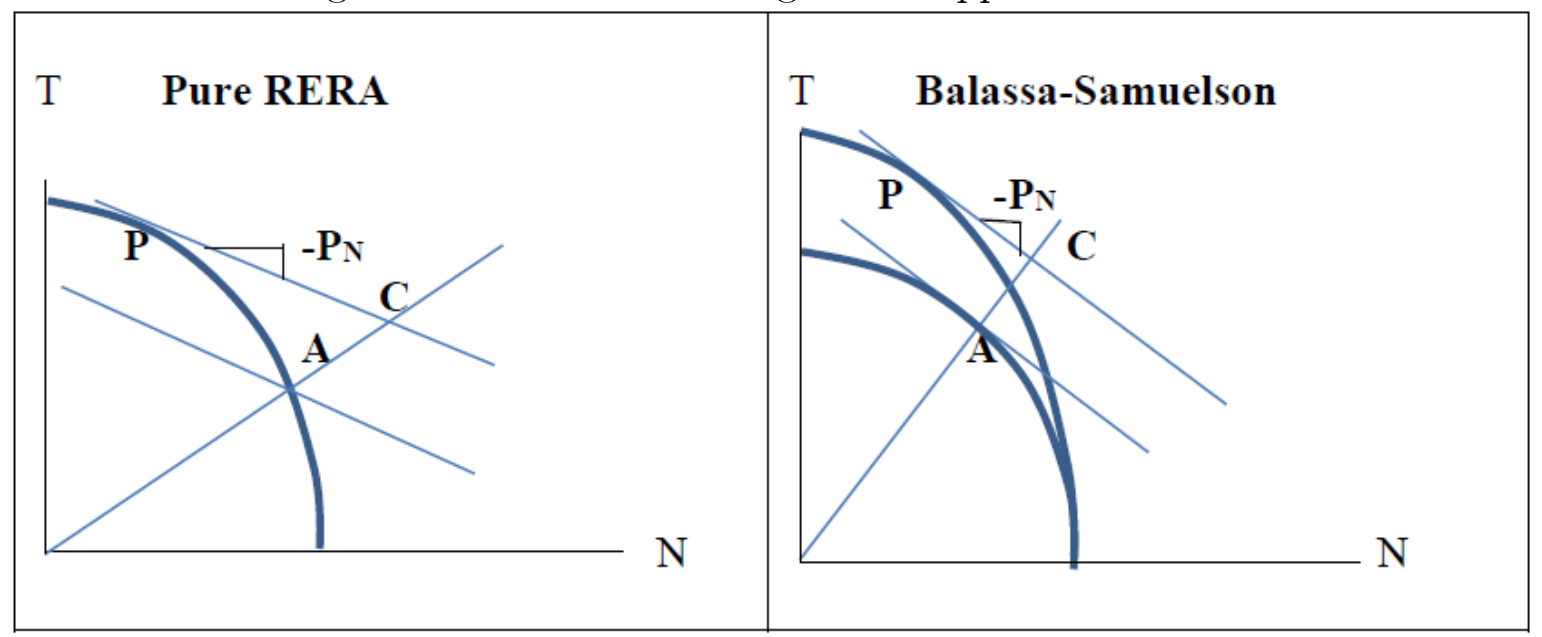

To our knowledge, a real appreciation originating with intra-national factor movements is a new idea in the literature. So it is natural to ask what kind of magnitude it might have in an actual economy.

production possibility frontier in Figure 1. 


\section{Input-output Simulation}

Now we will proceed to a calibration exercise for China, whose rural-urban labour flow surely counts as one of the most significant current developments in the global economy. The Chinese labour market is complex, and although the allocation of labour between tradables and nontradables production fits the precondition for a RERA - that rural output be predominantly nontradable - there are considerable variations in the orientation towards tradables and nontradables across sectors, and there are a number of other factors at play that affect China's real exchange rate. As a result, our calibration needs to be grounded on detailed input output tables to provide the sufficient sectorial detail. ${ }^{7}$

\subsection{The Use of Input-output Analysis}

Both Figure 1 and the model in Section 2, while useful to illustrate the possibility of a RERA, rely on a simple two-good world, where the two sectors are completely tradable and nontradable. In reality, any economy has multiple sectors with a degree of tradability in each. Our approach is to quantify a RERA allowing labour market mobility in an economy where there are many sectors, each differing in their degree of tradability. Rural output in China passes the accepted threshold of nontradability - the export share in output plus the import share in domestic sales is less than 20 per cent - but there is nevertheless a substantial amount of labour used for tradables which blurs our sharp distinction. ${ }^{8}$

\footnotetext{
${ }^{7}$ Some readers will recognize this as a computable general equilibrium framework (CGE). For a detailed discussion of the strengths and limitations of CGE modeling see Dixon and Rimmer (2013).

${ }^{8}$ Listing the database industries by tradability shows that both agricultural and nonagricultural goods contain tradable and nontradable components. A full listing of tradables industry mnemonics is: OthMeat, Logging, CrudeOilGas, FerrOre (Mining of Ferrous Metal Ores), FishProc, CottonTextil, TextProc, KnitMill, ClothesShoes, Leather, Furniture, CultureGoods, ToysSportEqp, BasicChem, OrganChem, SpecChemical, RubberPrd, Glass, China, IronProc, Boilers, MtlwrkMch (Manufacture of Metalworking Machinery), SpeclMch, SplEqpNEC (Manufacture of Other Special Purpose Machinery), Ships, OthTransEqp, Genratrs, HhldElec, ElcMchNEC, ElecCommsEqp (Manufacture of Communication Equipment), ElctronEqp, ElctronParts, HomeVideoTV, OthElecEqp, Meters, OfficeEqp, ArtsCrafts, OtherManufac, Air-
} 
Table 2: Hukou Categories

\begin{tabular}{ll}
\hline Item & Employment categories \\
\hline AG & AGriculture - Workers with rural residential status \\
& Rural Non-AGriculture - People in non-agriculture industries within their \\
& township of residence, such as in township and village enterprises and private \\
& enterprises in rural areas \\
RNAG & Rural-Urban Employment - Rural people in non-agriculture industries \\
RUE & outside of their township of residence \\
UUSE & Urban UnSkilled Employment - Urban people in unskilled occupations \\
USE & Urban Skilled Employment - Urban people in skilled occupations \\
\hline Unemployment categories \\
RAGU & $\begin{array}{l}\text { Rural AGricultural Unemployment }- \text { Rural workers without a job in their } \\
\text { township of residence }\end{array}$ \\
RUU & Rural-Urban Unemployment - Rural workers without a job outside their \\
township of residence \\
UU
\end{tabular}

The stylized description of all labour market restrictions in Section 2, using a single parameter $\psi$ is a brave simplification. Table 2 from Mai et al. (2014) lists no less than ten different groups of labour, each with different degrees of

Pass, CommerclSrvc, ResidentSrvc, RecreatSrvc. A full listing of Nontradables mnemonics is: Soybeans, Corn, Wheat, Rice, Millet, Vegetables, Apples, Citrus, Grapes, OtherCrops, Pigs, SheepGoats, OthLivestock, Cotton, Pork, Eggs, Milk, Forest, Fishing, OtherAg, CoalMineProc, NFerrOre, SaltMine, NMtlMine (Mining and Processing of Nonmetal Ores), GrainMillOil, AnimalFood, VegetOils, SugarRef, OtherFood, Wines, OtherBev, Tobacco, WoolTextiles, SilkTextiles, Sawmills, PaperProd, Printing, PetrolRef, Coking, Fertlizr, Pesticide, PaintsDyes, ChemDly (Manufacture of Chemical Products for Daily Use), Medicine, ChemFibre, PlasticPrd, Cement, Fireproof, NMtlMinPr (Manufacture of Graphite and Other Nonmetallic), IronSmelt, SteelSmelt, SteelProc, AlIronSmelt (Smelting of Ferroalloy), NFerrSmelt, NFerrProc, AgrMchn, RailEqp, MotorVhc, MVParts, Computers, Scrap, ElecSteam, GasSupply, WaterSupply, Construction, RailPass, RailFreight, RoadTrans, UrbanTrans, WaterTrans, AirFreight, PipeTrns (Transport via Pipeline), Warehousing, Post, Telecomms, ComputSrvc, Trade, Hotels, Restaurant, Finance, Insurance, RealEstate, Leasing, Tourism, Research, TechSrvc, GeolGeogTech (Geological Prospecting), WaterTechSvc, PublicSrvc, Education, Health, SocWelfare, ArtsFilmTV, Sports, PublicAdmin. 
mobility. We count rural emigration as emanating from category AG. From their 2002 database, the wage for AG is RMB 1200, the wage for RNAG is RMB 3840 and the wage for RUE is RMB 4800. Over all the categories of labour, the rural wage is approximately 40 per cent of aggregated non-rural wages which is what we use in our later simulations.

It seems highly plausible that rural wages in China would be below urban wages, due to the Hukou restrictions on rural-urban migration (Liu, 2005; Hertel and Zhai, 2006; Whalley and Zhang, 2007 and Knight, 2008). Yet this figure that the rural wage is about 40 per cent of that in Non-agriculture is not uncontroversial, and we shall presently advance some reasons to doubt it. ${ }^{9}$

An advantage of using input-output analysis is that it removes the presumption of a RERA because some urban sectors produce nontradables. For example, many rural workers come to be employed in urban construction, which is a service sector and intrinsically nontradable. It is therefore theoretically possible that rural-to-urban migration where workers end up in construction might attenuate or even dominate any tendency towards appreciation in our model. That is, if a (small) share of rural workers engaged in producing tradables was higher than the share of tradables production by workers who move to the city, the real exchange rate could in principle depreciate.

\subsection{CGE Simulations}

We conduct simulations with the CHINAGEM model. This is a 137 industry CGE model of China built with 2002 input-output data. The core CGE structure of CHINAGEM is based on ORANI, a static CGE model of the Australian economy (Dixon et al., 1982). The wide use of the CHINAGEM model for policy analysis makes it an attractive tool, since we are particularly interested in any real world

\footnotetext{
${ }^{9}$ For a previous analysis of the effects of partially closing the wage gap through relaxation of the Hukou system, see Mai et al. (2014). Our empirical analysis differs from theirs by considering different configurations of the model to isolate the different mechanisms.
} 
constraints that might mitigate or overturn the simple appreciation story in our model, and in Figure 1. ${ }^{10}$

In CHINAGEM, production is modelled using nested constant elasticity of substitution (CES) and Leontief production functions which allow substitution between domestic and imported sources of produced inputs and between labour, capital and land. The production functions are subject to constant returns to scale with a 0.5 elasticity of substitution between capital and labour. Household demand is modelled by the linear expenditure system (ELES). Trade is modelled using the Armington assumption for import demand and a constant elasticity of transformation (CET) for export supply. China is considered as a small open economy in import markets with foreign import prices determined in world markets. CHINAGEM adopts the Armington assumption that imports are imperfect substitutes for domestic supplies. The value of elasticity of substitution between import and domestic products for all commodities in the CHINGEM model is 2.

Exports are demanded according to constant-elasticity demand curves for most commodities. Export demand elasticities give the percentage change in world demand for Chinese exports with respect to a 1 per cent increase in world price of the Chinese product. The value of the elasticities for China's main exported products is -4 in the CHINAGEM model.

The approach we take to our simulations is to outline some mechanisms that could have been important for a recent appreciation of the Chinese real exchange

\footnotetext{
${ }^{10} \mathrm{~A}$ variant of this model, called SICGE, has been applied by and on behalf of several Chinese organizations (personal communication, Centre of Policy Studies, Victoria University). These include the State Information Centre (SIC) at the National Development and Reform Commission (NDRC), the Ministry of Agriculture, the National School of Development at Peking University, Renmin University of China, Hunan University, the Chinese Academy of Sciences, the Shenzhen Academy of Social Sciences, China Institute of Water Resources and Hydropower Research, and Nanjing Agricultural University. Among the topics covered are: labour market reform, including changes to the household registration system and introduction of social security coverage for rural migrant workers (Mai and Peng, 2012; Mai.et al., 2014); increasing labour costs; property taxes; social housing projects; oil prices (Zhang and Li, 2010); China's GFC stimulus package (Mai and Dong, 2011); transportation development and related energy demand; climate change (Wang et. al., 2011); liberalization of the interest rate; and renewable energy.
} 
rate, recognizing that there are many other factors at play alongside a RERA. Between 2000 and 2013 the Chinese currency appreciated by around 40 per cent against the US dollar, and given that Chinese inflation persisted into the worldwide Great Recession, unlike OECD inflation, it can be surmised that the real exchange rate appreciated by at least that much. Furthermore, given the substantial buildup of foreign reserves (GFE), it might be expected that in the absence of this the exchange rate (real and nominal) might have appreciated even further.

Figure 2: Chinese Exchange Rate Appreciation

\begin{tabular}{|c|c|c|c|}
\hline 45000 & & 150.00 & \\
\hline 40000 & & 140.00 & \\
\hline 35000 & & 130.00 & \\
\hline 30000 & & 120.00 & \\
\hline 25000 & & 110.00 & \\
\hline 20000 & 1 & 100.00 & $-\quad-$ GFE LHS \\
\hline 15000 & 1 & 90.00 & US/Y index RHS \\
\hline 10000 & 1 & 80.00 & \\
\hline & 1 & 70.00 & \\
\hline 0 & --7 & 60.00 & \\
\hline & 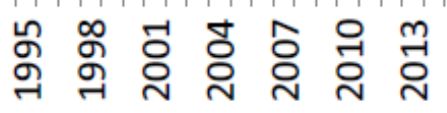 & & \\
\hline
\end{tabular}

Source: NBSC (2014) website

Figure 2 is given with our previous caveat in place. If the price of tradables increases as a result of the nominal appreciation, the exchange rate definition that is relevant for the model of Section 2 - namely the relative price of nontradables - may move much less than indicated by Figure 2. Our approach will be to calibrate the CGE model to the 40 per cent for the standard definition $s p / p^{f}$ in Figure 2 and accept the corresponding change in relative price of nontradables that the model generates. The latter is not directly observable, depending as it does on complex measurements from the database about tradability of goods in 
different sectors.

As seen in Figure 3, since 2000 employment in agriculture has fallen by about 30 per cent. This is a significant amount in its own right, and the rate of decline accelerated compared with previous years coinciding with a series of Hukou reforms and with the mechanization of agriculture (Zhang et al. 2015). In Figure 3 , roughly half of the decline since 2000 can be attributed to this acceleration. ${ }^{11}$

Figure 3: Rural Population Share

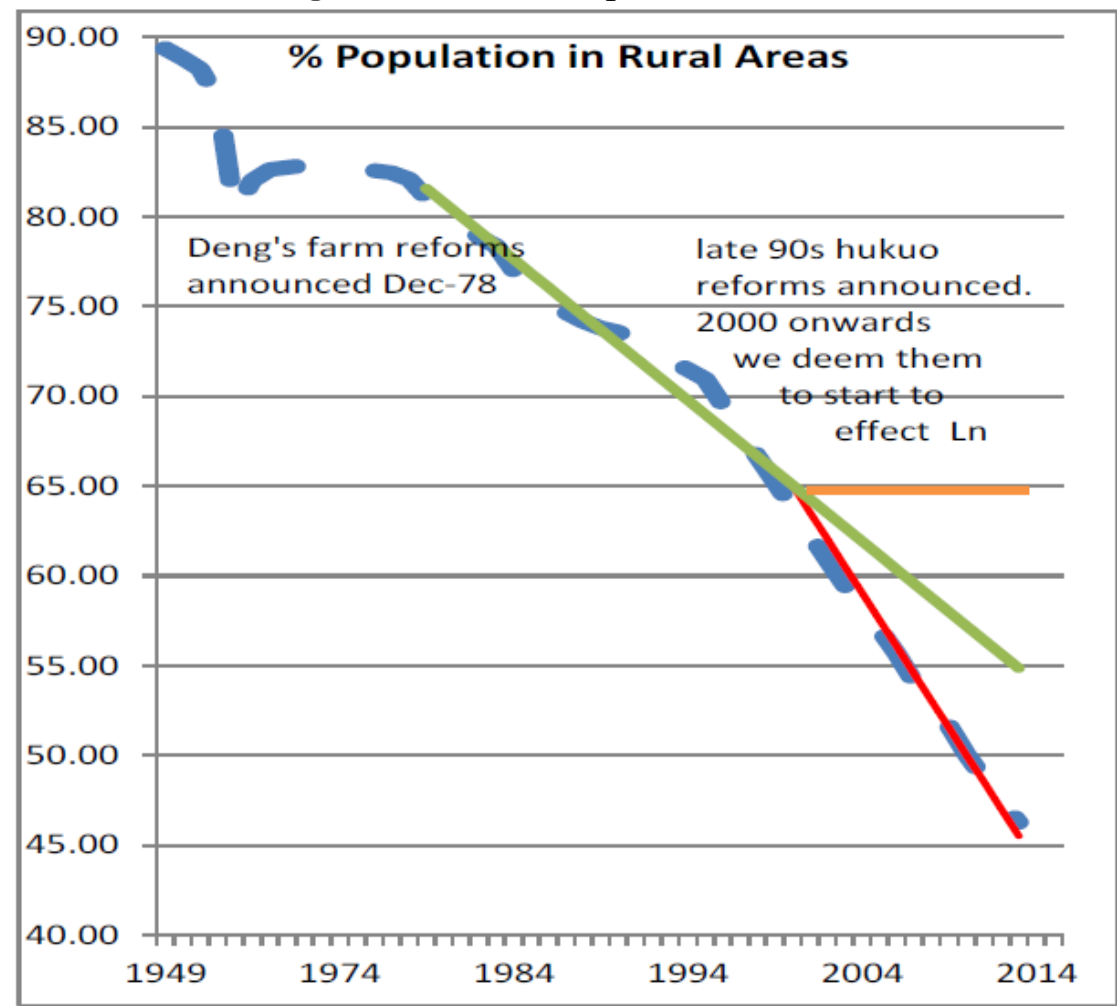

Source: Table 2-1, NBSC (2014)

In this paper we have outlined a theoretical inter-connection between intranational labour movements and exchange rate, and we shall illustrate this using the CHINAGEM model. We have in the previous section given a simple theoretical argument which suggests that appreciation can be partly explained by

\footnotetext{
${ }^{11}$ Figure 3 contains data for population. Since we are using proportional changes for the analysis we are implicitly assuming that the proportions of rural workers are the same.
} 
relaxation of Hukou system and a consequent movement of labour from agriculture to urban activities, and we shall add some other factors in this section which seem relevant from China's recent experience.

In Table 3, we use the CHINAGEM model to build up an explanation of Chinese appreciation and the movement in labour between agriculture and the rest of the economy. In the simulations reported in Table 3, we hold constant the total availability of labour and capital, although both are mobile within the economy. ${ }^{12}$ We also assume that there was no increase in total factor productivity. Thus we abstract from overall economic growth to focus on factors that changed relative prices in China (particularly the real exchange rate) and the composition of economic activity.

Table 3: Using CHINAGEM to Uncover Factors Driving Developments in China between 2000 and 2013 (percentage effects)

\begin{tabular}{|c|c|c|c|c|}
\hline simulation & $\begin{array}{l}\text { Prefer- } \\
\text { ences } \\
\text { (1) }\end{array}$ & $\begin{array}{l}\text { Hukou } \\
\text { (2) }\end{array}$ & $\begin{array}{l}\text { Mechan- } \\
\text { ization } \\
\text { (3) }\end{array}$ & $\begin{array}{l}\text { Export } \\
\text { Productivity } \\
\text { (4) }\end{array}$ \\
\hline Ratio, agricultural to non-agricultural wage rates & 0.00 & 30.00 & 30.00 & 30.00 \\
\hline $\begin{array}{l}\text { Real exchange rate measure } 1 \text { : price level in China } \\
\text { relative to that in trading partners in same currency }\end{array}$ & -1.81 & -0.98 & -2.01 & 40.00 \\
\hline $\begin{array}{l}\text { Real exchange rate measure } 2 \text { : ratio, prices of non- } \\
\text { traded to prices of traded goods }\end{array}$ & -0.94 & 1.16 & 0.42 & 5.45 \\
\hline Employment in agriculture & -14.57 & -17.35 & -30.00 & -30.00 \\
\hline Capital/labour $(\mathrm{K} / \mathrm{L})$ ratio in agriculture & -10.14 & 4.73 & 159.69 & 157.31 \\
\hline Terms of trade & -1.00 & -1.09 & -1.47 & 30.28 \\
\hline
\end{tabular}

We start in Column (1) of Table 3 by looking at the effects of changes in the commodity composition of household expenditures. Over recent decades the share of the household budget devoted to food has fallen substantially as shown in

\footnotetext{
${ }^{12}$ In the theoretical model, there was a close link between foreign-owned capital and productivity, as evidenced by terms like $A_{T} / r$ in (9). That is, more capital from overseas via a lowering of the required rate of return $r$ is equivalent to an increase in tradables productivity. In a similar way, in these simulations we do not allow foreign-owned capital inflow explicitly but we do later discuss an increase in tradables productivity which would have a similar effect. We have calibrated the ownership of capital in the CGE model to the 2002 database when almost all of it (91 per cent) was domestically owned.
} 
Table 4 (from Zhou et al., 2012). In passing we note that this resonates with our representative agent assumption in that rural and urban households consume a similar share of food in their consumption basket, and, that whatever differences there are have been narrowing in recent years.

Table 4: Share of Income Devoted to Food Consumption

\begin{tabular}{|c|c|c|c|}
\hline Year & Rural & Urban & Average \\
\hline 1978 & 67.7 & 57.5 & 62.6 \\
\hline 2000 & 49.2 & 39.2 & 44.2 \\
\hline 2010 & 41.0 & 35.7 & 38.4 \\
\hline
\end{tabular}

Source: Zhou et al. (2012)

We surmise this has been driven by economic development, which tends to cause a low expenditure elasticity of the demand for food (Gollin et al., 2004). In the static no-growth framework that we have adopted for our analysis we capture the change in the composition of household demands as a preference shift (change in the parameters of the utility function, like a fall in $\theta$ in Section 2). Column (1) of Table 3 shows the effects of a preference shift against food that moves the household budget share down by 20 percentage points. In doing so, we are allowing for rigidity in the Chinese labour market, so that developments in preferences for food prior to 2000 in Table 4, and their attendant effects on rural labour, are played out from 2000 onwards.

The predictions of our simple model in $2.2(d)$ were $\hat{p}=0$ and $\hat{L}_{N}=\hat{\theta}\left(L_{T} / L_{T}^{*}\right)$. That is, rural labour would emigrate without any changes in the real exchange rate. Unlike our simple model, however, there is downward pressure apparent in column (1) of Table 3, for both measures of the real exchange rate. This is because land is a fixed factor, and the departing labour reduces the return to land and lowers agricultural costs. ${ }^{13}$

An important prior assumption underlying column (1) of Table 3 is that

\footnotetext{
${ }^{13}$ In agriculture, the cost shares over labour, capital and land are 82 per cent, 12 per cent and 6 per cent. In non-agriculture the corresponding shares are 52 per cent, 41 per cent and 1 per cent.
} 
the preference shift has no effect on the ratio of agricultural to non-agricultural wages. The preference shift reduces the demand for agricultural labour. Rather than allowing this to reduce rural wages, we assume in this column that there is a sufficient flow of rural workers to urban occupations to prevent a decline in the agriculture/non-agriculture wage ratio. As can be seen in column (1) of Table 3 , under this assumption the preference shift explains a reduction in agricultural employment of 14.75 per cent.

We also allow for labour movement which is driven endogenously by workers pursuing a higher standard of living in the cities, as in Lewis (1954). In column (2) of Table 3 we introduce a notional movement, 30 per cent, in the agriculture/nonagriculture wage ratio. We visualize this as being associated with relaxation in Hukou system. Unlike column (1) the labour movement puts downward pressure on urban wages and upward pressure on rural wages, ceteris paribus.

Xue and Gao (2012) mount a compelling case that the statistics related to urban and rural wage rates are poorly measured, and so we are aware that the wage gap closure we chose to impute could be challenged. The urban-to-rural wage ratio exhibits persistently high values around 3.0, though it peaked in 20072009 and has come off about 10 per cent since then (NBSC, 2014). ${ }^{14}$ As shown in Figure 4 this recent period has been associated with heightened market pressure from the unregistered urban immigrants, which should put downward pressure on urban wages and upward pressure on rural wages. Xue and Gao's concern revolves around the measurement of workers who are away from their registered places of abode in unregistered employment.

"China's current official official household survey has failed to effectively cover the rural-to-urban migrants, which overstates the income of urban residents and understates the income of rural residents, and then overstates the urban-rural income gap in China." Xue and Gao (2012), Abstract

\footnotetext{
${ }^{14}$ The measure of urban-to-rural wage ratio is the Per Capita Income of Urban and Rural Households in Table 6-4 in NBSC (2014).
} 
If this is correct, and more workers are in fact in this category as Hukou is dismantled, then the published ratio has limited value. We scale up the recent decline three-fold in view of the dramatic growth of unregistered urban immigrants evident in Figure 4.

Figure 4: Hukou Violations

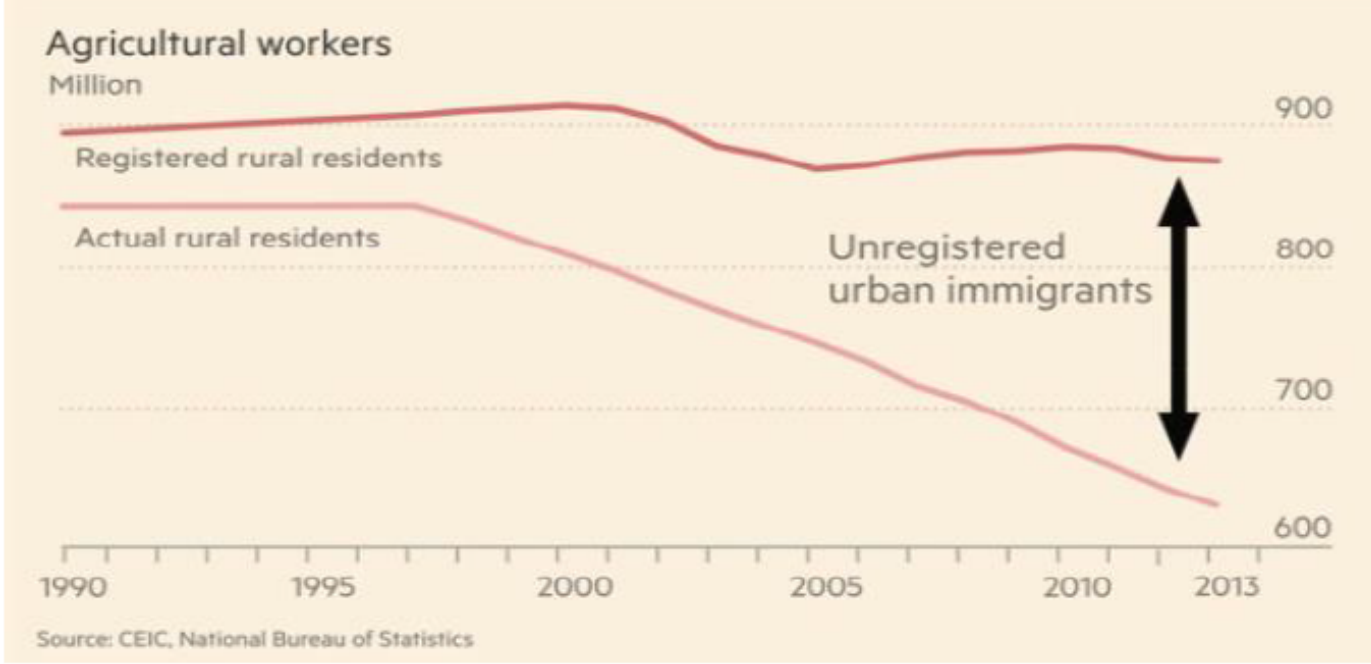

Source: Financial Times (2015)

With the 30 per cent increase in the wage ratio, the reduction in agricultural employment moves from 14.57 per cent to 17.35 per cent. The real exchange rate moves up by 1 or 2 per cent depending on which measure is adopted (from -1.81 to -0.98 or from -0.94 to 1.16 ). This is our calibration of the RERA for this period of China's history. Both the appreciation and the associated movement in labour out of agriculture are quite small, but this just reflects our assumption that the gap has not come close to closing. This in turn implies there is a latent RERA waiting to display itself as China develops further and the wage gap closes further.

Thus the predictions of our simple model in 2.2 (b), namely $\hat{p}=\left(1-\alpha_{N}\right) \hat{\psi}$ and $\hat{L}_{N}=-\hat{\psi} / 2$ are confirmed qualitatively, in that labour leaves rural industries and the exchange rate appreciates. However, for a $\hat{\psi}$ of 30 per cent and a cost 
share of capital in nontradables $\left(\alpha_{N}\right)$ of 12 per cent, the effects in CHINAGEM are clearly much smaller. This reflects the fact that agriculture is one among many sectors in CHINAGEM, not one among two sectors. ${ }^{15}$

In Column (3) of Table 3 we introduce cost-neutral capital-using/laboursaving technical change in the agricultural sector, sufficient to bring the movement of labour out of agriculture up to 30 per cent. We think it is reasonable to suppose that an increase in rural wages together with departure of labor to urban activities has been accompanied by increased mechanization. As can be seen from Table 3, the effect of our mechanization assumption is to increase the $K / L$ ratio in agriculture by about 148 per cent, i.e., from an increase of 4.73 per cent in Column (2) to an increase of 159.69 per cent in Column (3). This may seem dramatic. However, the $K / L$ ratio was initially low, about 15 per cent. A 159.69 per cent increase takes the $K / L$ ratio to 38 per cent. This is consistent with strong investment in agriculture driven by reductions in employment.

Compelling evidence for higher capital-labour ratios appears in Table 5 (from Zhi, 2013). Since 2004, there has been a sizable increase in food machinery use, measured by KVolts drawn, and in the euro denominated value of machinery. The latter is particularly notable during a period of Chinese nominal currency strength (Figure 2). Since output did not increase dramatically (Column 1 of Table 5) and many rural workers left for the cities (Figures 3 and 4) our simulated increases in the capital-labour ratios do not appear implausible.

Mechanisation has been an integral part of the transformation of agriculture as reviewed in Zhang et al. (2015). Since 2000, the Central Committee of the Chinese Communist Party has, in its annual No. 1 Central Policy Documents, announced several measures to modernize and mechanize agriculture. These measures can be seen both as a response to Lewis-style depopulating of agricultural areas and as a stimulus to further intra-national migration. They include re-

\footnotetext{
${ }^{15}$ Of the 95 nontradable industries in CHINAGEM 20 are agricultural, and of the 115 nonagricultural industries 75 are nontradable.
} 
ducing rural taxes (2003) which had been a tool for regional governments to counteract central fiscal consolidation, building infrastructure (2005, 2007, 2008 and 2011 with the latter being focussed on irrigation), encouraging technological innovation (2005, 2007 and 2008) and mechanization (2009) supported by more technical staff (2012) and rural finance institutional reform (2014).

Table 5: Rural Mechanization*

\begin{tabular}{|c|c|c|c|}
\hline & Food Production & Value of Agricultural Machinery & Agricultural Machinery Power \\
\hline 2004 & 4.69 & unavailable & 6.4 \\
\hline 2008 & 5.29 & 199 & 8.2 \\
\hline 2012 & 5.90 & 406 & 10.2 \\
\hline
\end{tabular}

is in Euro 100 million, and "Agricultural Machinery Power" is in 100 million KVolts; Source: Zhi (2013).

Although Column (3) of Table 3 incorporates believable increases in the wage ratio and the movement in people from agriculture to non-agriculture, it shows a negligible movement in the real exchange rate, however measured. So how can we explain real appreciation while imposing the observed movements in agricultural employment and relative wages?

Our answer is to assume that there was strong outward movement in exportdemand curves largely as a result of China's accession to the World Trade Organization (WTO). We found that the observed real appreciation, 40 per cent on measure 1 and a 6 per cent raise in the relative prices of nontradables, together with observed movements in agricultural wages and employment, could be explained by an outward shift in export-demand curves equivalent to a 30.28 per cent improvement in the terms of trade. This terms-of-trade-equivalent increase in export demand could be driven by a perception of improved quality of Chinese goods in parallel with the accession to the WTO in 2001.

This shock is somewhat like a Balassa-Samuelson effect, outlined in $2.2(a)$, though it is an improvement in productivity in production for export as opposed 
to a general productivity improvement in tradables. We opted for this modelling device because some WTO outcomes are targeted to exporting in particular, such as the elimination of foreign import quotas, rather than tradables in general. The WTO accession spawned a renaissance of labour intensive manufacturing, with textiles and apparel exports to the US and Western Europe gaining the most from the new low-quota status. Martin and Ianchovichina (2003) put the benefit of the WTO status (including the lead up) at around $\$$ US40 billion which is about 20 per cent of China's total exports in 2000 of around $\$ 200$ billion (Berger and Martin, 2011). This goes a sizable way towards the figure just over 30 per cent in Column (4) of Table 3.

In CHINAGEM, as well as in our simple model, there is no conceptual conflict between Balassa-Samuelson-style effects and a dual economy structure, as we noted in $2.2(c)$. So the shocks can be sensibly combined, as we have done in Table 3, or sensibly decomposed, as we now do in Table 6 . The first column of Table 6 is the results in Column (4) of Table 3. Then columns (1) to (4) of Table 6 decompose these results into the parts attributable to preference changes, relaxation of Hukou, agricultural mechanization and export productivity. The results in Column (1) of Table 6 are approximately those in Column (1) of Table 3. The results in Column (2) of Table 6 are approximately the difference between those in Columns (2) and (1) of Table 3. The results in Column (3) of Table 6 are approximately the difference between those in Columns (3) and (2) of Table 3, and the results in Column (4) of Table 6 are approximately the difference between those in Columns (4) and (3) of Table 3. That these relationships are only approximate reflects the non-linearity of the CHINAGEM model.

Table 6 implies that the predominant cause of Chinese real appreciation was changes in export productivity or quality [Column (4)]. Nevertheless, the Lewis effect [Column (2)] identified in this paper made a noticeable contribution to the real exchange rate movement especially under measure 2 where it accounts for 
around one third of the total movement.

Table 6: CHINAGEM decomposition* results for China, 2000-2013 (percentage effects)

\begin{tabular}{|c|c|c|c|c|c|}
\hline & Total: & $\begin{array}{l}\text { Prefer- } \\
\text { ences }\end{array}$ & Hukou & $\begin{array}{l}\text { Mechan } \\
\text {-ization }\end{array}$ & $\begin{array}{l}\text { Export } \\
\text { product- } \\
\text { ivity }\end{array}$ \\
\hline & & (1) & (2) & (3) & (4) \\
\hline Ratio, agricultural to non-agricultural wage rates & 30.00 & 0.00 & 30.00 & 0.00 & 0.00 \\
\hline $\begin{array}{l}\text { Real exchange rate measure } 1 \text { : price level in China } \\
\text { relative to that in trading partners in same } \\
\text { currency }\end{array}$ & 40.00 & -2.04 & 0.89 & -1.45 & 42.56 \\
\hline $\begin{array}{l}\text { Real exchange rate measure } 2 \text { : ratio, prices of non- } \\
\text { traded to prices of traded goods }\end{array}$ & 5.45 & -0.79 & 2.03 & -0.66 & 4.97 \\
\hline Employment in agriculture & -30.00 & -12.76 & -4.33 & -12.52 & -0.28 \\
\hline Capital/labour $(\mathrm{K} / \mathrm{L})$ ratio in agriculture & 157.31 & -13.00 & 21.01 & 148.88 & -0.35 \\
\hline Terms of trade & 30.28 & -1.03 & -0.31 & -0.46 & 32.14 \\
\hline
\end{tabular}

*: The total column is decomposed according to the method set out in Harrison, W.J., J.M. Horridge and K.R. Pearson (2000), "Decomposing simulation results with respect to exogenous shocks", Computational Economics, 15, pp. 227-249.

\section{Conclusion}

In this paper we have used the CHINAGEM model to validate a simple theoretical idea - that intra-economy labour movements can have exchange rate effects. To our knowledge, this is new to the literature.

Naturally, a great deal has occurred in China over the years of our calibration exercise, and, the wage gap between urban and rural areas is still very large. We find an important role for changing tastes and labour saving technical progress in explaining labour movement. There is also a role for the WTO in explaining exchange rate changes. Our analysis is complicated by the fact that the measures of the real exchange rate respond differently to shocks. This is because the division between tradables and nontradables is much harder to make in practice 
than it is in theory. Nevertheless, the ambiguity of the model measures of the exchange rate is not out of line with other studies that find relatively small real exchange rate effects originating with non-traded goods' prices, with a large contribution coming from variations in the prices of traded goods (Engel, 1999, Betts and Kehoe, 2008). If the law of one price held for tradables, then this could not occur.

All these caveats aside, our paper has outlined a new connection between labour movements and the real exchange rate. Our simulations show how the mechanization in Chinese agriculture and a decline in the utility taste of food obscure this effect, by holding down the price of nontradables. Like everyone else labouring in this intellectual field, we look forward to better data on the wage gap between rural and urban areas, to enable more precise decompositions of labor movements in future research. Be that as it may, eventually the large wage gap still existing between rural and urban areas will narrow substantially as Chinese development draws to a close, and with it a further rural-led real appreciation is to be expected.

\section{References}

[1] Balassa, B. (1964), "The Purchasing Power Parity Doctrine: a Reappraisal", Journal of Political Economy, 72 (December), 584-596.

[2] Berger, B. and Martin, R. (2011), "The Growth of Chinese Exports: An Examination of the Detailed Trade Data", Board of Governors of the Federal Reserve System, International Finance Discussion Papers, No. 1033.

[3] Betts, C. and Kehoe, T. J. (2008), "Real Exchange Rate Movements and the Relative Price of Non-traded Goods", NBER Working Papers, No.14437. 
[4] Cardi, O. and Restout, R. (2015), "Imperfect Mobility of Labor across Sectors: a Reappraisal of the Balassa-Samuelson Effect", Journal of International Economics, 97(2), 249-265.

[5] Canzoneri, M., Cumby, R. and Diba, B. (1999), "Relative Labor Productivity and the Real Exchange Rate in the Long Run: Evidence for a Panel of OECD Countries", Journal of International Economics, 47 (2), 245-266.

[6] Caselli, F. (2005), "Accounting for Cross-Country Income Differences", Handbook of Economic Growth, Vol. 1B, edited by Philippe Aghion and Steven Durlauf, Elsevier, Amsterdam.

[7] Chan, K.W. (2010), "The Household Registration System and Migrant Labor in China: Notes on a Debate", Population and Development Review, 36 (2), 357-364.

[8] De Gregorio, J., Giovannini, A. and Wolf, H. (1994), "International Evidence on Tradables and Nontradables Inflation", European Economic Review, 38(6), 1225-1244.

[9] Dixon P., Parmenter B., Sutton J. and Vincent, P. (1982), "ORANI: a Multisectoral Model of the Australian Economy", North-Holland, Amsterdam

[10] Dixon, P. and Rimmer, M. (2013), "Validation in CGE modeling", Chapter 19, 1271-1330 in P.B. Dixon and D.W. Jorgenson (editors), Handbook of Computable General Equilibrium Modeling, Elsevier.

[11] Dumrongrittikul, T. (2012), "Real Exchange Rate Movements in Developed and Developing Economies: a Reinterpretation of the Balassa-Samuelson Hypothesis", Economic Record, 88, 537-553.

[12] Engel, C. (1999), "Accounting for US Real Exchange Rate Changes", Journal of Political Economy, 107 (3), 507-537. 
[13] Fei, J. C. H. and Ranis, G. (1964), "Development of the Labour Surplus Economy: Theory and Policy", Homewood, III: Irwin.

[14] Financial Times (2015), "China Migration: Policy Bottlenecks Add to Labour Shortage", Financial Times, 4 May.

[15] Gollin, D., Lagakos, D. and Waugh, M. (2014), "The Agricultural Productivity Gap", Quarterly Journal of Economics, 129 (2): 939-993.

[16] Gollin, D., Parente, S. and Rogerson, R. (2004), "The Food Problem and the Evolution of International Income Levels", Economic Growth Centre Discussion Paper 899 (December), Yale University.

[17] Guo, Q. (2010), "The Balassa-Samuelson Model of Purchasing Power Parity and Chinese Exchange Rates", China Economic Review, 21, 334-345.

[18] Harris, J. and M. Todaro (1970), "Migration, Unemployment and Development: a Two-Sector Analysis", American Economic Review, 60(1), 126-142.

[19] Hayashi, F. and Prescott E. (2008), "The Depressing Effect of Agricultural Institutions on the Prewar Japanese Economy", Journal of Political Economy, 116(4), August, 573-632.

[20] Hertel, T. and F. Zhai (2006), "Labour Market Distortions, Rural-urban Inequality and the Opening of China's Economy", Economic Modelling, 23, 76-109.

[21] Hu, D. and Su, J. (2013), "Government Consumption, Terms of Trade, Productivity and RMB Exchange Rate: Evidence from Study on Extension of Balassa-Samuelson Hypothesis", Finance Study (in Chinese), 10, 42-54.

[22] Jorgenson, D. W. (1961), "The Development of a Dual Economy", The Economic Journal, 71(282), 309-334. 
[23] Kakkar, V. (2003), "The Relative Price of Nontraded Goods and Sectoral Total Factor Productivity: an Empirical Investigation", Review of Economics and Statistics, 85(2), 444-452.

[24] Knight, J. (2008), "Reform, Growth and Inequality in China", Asian Economic Policy Review, 3, 140-158.

[25] Kravis, I., Heston, A., and Summers, R. (1978), "International Comparisons of Real Product and Purchasing Power", Baltimore, The Johns Hopkins University Press

[26] Kravis, I., Heston, A., and Summers, R. (1983), "The Share of Services in Economic Growth," in F. G. Adams and Bert Hickman, (eds.), Global Econometrics: Essays in Honor of Lawrence R. Klein, Cambridge, Mass., the MIT Press, 188-218.

[27] Lane P., Milesi-Ferretti G. (2002), "External wealth, the Trade Balance, and the Real Exchange Rate", European Economic Review, 46 (6), 1049-1071

[28] Lewis W. A (1954), "Economic Development with Unlimited Supplies of Labour", The Manchester School, 22(2), 139-191.

[29] Lin J. (2007), "Thoughts and Policy Suggestions on the RMB Exchange Rate Problems", World Economy (in Chinese), 3, 1-12

[30] Liu, Z (2005), "Institution and Inequality: the Hukou System in China", Journal of Comparative Economics, 33, 133-157.

[31] Lu F. and Liu L. (2007), "Measurements of China's Relative Labor Productivity Growth (1978-2005): Rethinking the Relationship between BalassaSamuelson Effect and RMB Real Exchang Rate", China Economic Quarterly (in Chinese), 6 (2), 357-380. 
[32] Mai, Y., and Dong X. (2011), "Reducing Tax, Domestic Demand, and New Growth Model: a Dydnamic CGE Analysis" in Li, C., and Li, Y., eds. China Economy Development Strategy, Modern Economic Development Strategy Series, No. 9. Intellectual Property Right Publishing House, China.

[33] Mai, Y. and X. Peng, (2012), "Estimating the Size of Rural Labour Surplus in China - a Dynamic General Equilibrium Analysis", The Chinese Economy, 45 (5), 38-59.

[34] Mai, Y., Peng, X., Dixon, P. and Rimmer, M. (2014), "The Economic Effects of Facilitating the Flow of Rural Workers to Urban Employment in China", Papers in Regional Science, 93(3), 619-42.

[35] Martin, W. and E. Ianchovichina (2003), "Economic Impacts of China's Accession to the World Trade Organization", World Bank Policy Research Papers.

[36] Milton, G., and Kravis, I. (1954), "An International Comparison of National Products and the Purchasing Power of Currencies: A Study of the United States, The United Kingdom, France, Germany and Italy", OEEC, Paris.

[37] NBSC (2014), China Statistical Yearbook 2014, National Bureau of Statistics in China, China Statistics Press.

[38] Obstfeld, M. and Rogoff., K. (1996), "Foundations of International Macroeconomics", MIT Press, Cambridge Massachusetts.

[39] Ranis, G. and Fei, J. C. H. (1961), "A Theory of Economic Development", American Economic Review, 51(4), 533-565.

[40] Ray, D. (2011), Development Economics, Princeton University Press 
[41] Restuccia, D., Yang, T., Zhu, D.(2008), "Agriculture and Aggregate Productivity: A Quantitative Cross-country Analysis", Journal of Monetary Economics, 55(2), 234-250.

[42] Rybczynski, T. M. (1955), "Factor Endowments and Relative Commodity Prices", Economica, 22, 336-341.

[43] Samuelson, P. A. (1964), "Theoretical notes on trade problems", Review of Economics and Statistics, 46, 145-154.

[44] Samuelson, P. (1994), "Facets of Balassa Samuelson Thirty Years Later", Review of International Economics, 2(3), 201-226.

[45] Shultz, T. W. (1953), "The Economic Organization of Agriculture", McGraw Hill, New York.

[46] Tang X. and Qian S. (2007), "The Impact of Relative Labor Productivity Changes on RMB Real Exchange Rate: an Empirical Analysis based on the BS effect", Finance Study (In Chinese), 5, 1-14.

[47] Tyers R. and Zhang Y. (2011), "Appreciating the Renminbi", The World Economy, 34(2), 265-297.

[48] Vollrath, D. (2009), "How Important Are Dual Economy Effects for Aggregate Productivity?", Journal of Development Economics, 88(2), 325-334.

[49] Wang, X., Li, J. and Zhang, Y. (2011), "An Analysis on the Short-term Sectoral Competitiveness Impact of Carbon Tariff in China", Energy Policy, $39(7), 4144-4152$.

[50] Wang Z.and Yao Y. (2009), "Structural Transformation and BalassaSamuelson Effect", World Economy (In Chinese), 4, 38-49. 
[51] Whalley, J. and Zhang, S. (2007), "A Numerical Simulation Analysis of (Hukou) Labour Mobility Restrictions in China", Journal of Development Economics, 83, 392-410.

[52] Xue, J. and W. Gao (2012), "How Large is the Urban-Rural Income Gap in China?" Conference paper: China and the World Economy, March 16-18, 2012, Seattle.

[53] Zhang, Y. and J. Li (2010), "An Analysis on the Effect of Rising Oil Prices on the Economic System in China", The Reform (in Chinese), 8.

[54] Zhang M. (2012), "RMB Exchange Rate Appreciation: Retrospect, Mechanism and Prospect", Finance Review (in Chinese), 2, 12-25

[55] Zhang, Q., Oya, C. and Ye J. (2015), "Bringing Agriculture Back In: The Central Place of Agrarian Change in Rural China Studies", Journal of Agrarian Change, 15(3), 299-313.

[56] Zhi, C. (2013), "China's Agricultural Machinery Industry: A Global Perspective", speech at Regional Forum on Sustainable Agricultural Mechanization in Asia and the Pacific, 26-27 October 2013, Qingdao, China.

[57] Zhou, Z., Tian, W., Wang, J., Liu, H. and Cao, L. (2012), "Food Consumption Trends in China", report submitted to Australian Government Department of Agriculture, Fisheries and Forestry. 


\section{Appendix: General RERA Model}

In this appendix we present a general RERA model, with the basic environment still following Section 2.1, but we add some new notations, and now technology and preferences sit within a wider class of linear homogenous functions. The production technology in the tradable and nontradable sector is as follows,

$$
Y_{T}=A_{T} F\left(K_{T}, L_{T}\right)=A_{T} L_{T} f\left(k_{T}\right), Y_{N}=A_{N} G\left(K_{N}, L_{N}\right)=A_{N} L_{N} g\left(k_{N}\right),
$$

where $k_{j}=K_{j} / L_{j}$ is the capital-labour ratio in Sector $j, j \in\{T, N\}$.

Similarly, the full set of first order conditions from maximizing profits, which define a general equilibrium for $\left(k_{T}, k_{N}, w, p\right)$, are,

$$
\begin{aligned}
A_{T} f^{\prime}\left(k_{T}\right) & =r, \\
A_{T}\left[f\left(k_{T}\right)-k_{T} f^{\prime}\left(k_{T}\right)\right] & =w, \\
p A_{N} g^{\prime}\left(k_{N}\right) & =r, \\
p A_{N}\left[g\left(k_{N}\right)-k_{N} g^{\prime}\left(k_{N}\right)\right] & =\psi w
\end{aligned}
$$

From (15), we derive $k_{T}\left(r, A_{T}\right)=f^{\prime^{-1}}\left(r / A_{T}\right)$, and from (16), $w\left(r, A_{T}\right)=$ $A_{T}\left[f\left(k_{T}\right)-k_{T} f^{\prime}\left(k_{T}\right)\right]$. With $w$ tied down by (15) and (16), and the RHS of both (17) and (18) fixed, (17) and (18) are implicitly functional maps between $p$ and $k_{N}$. In $p \times k_{N}$ space, (17) is upward sloping and (18) is downward sloping, so there is a unique solution for $p$ and $k_{N} \cdot{ }^{16}$

In equation (18), there is an institutional barrier to prevent free labor mobility from the rural (nontradable) to urban (tradable) sector. Hence, the wage rate in nontradable is the ratio $\psi$ of the tradable wage rate: $w_{N}=\psi w, \psi \in(0,1]$. The model solves for a unique $L_{N}$, given $\psi$ (see more details later). Therefore, it does not matter if the $\psi$ restriction is written in terms of $L_{N}$, or $w$. See eq. (25) below.

\footnotetext{
${ }^{16}$ If $p$ rises in (17), $A_{N}$ and $r$ being fixed, $g^{\prime}$ (the mpk net of technology) must fall and this occurs as the capital-labour ratio $k_{N}$ rises. Contrariwise, with $w$ fixed, if $p$ rises in (18), it requires a fall in $g-g^{\prime} k_{N}$ (the mpl of technology) and this occurs as the capital-labour ratio falls.
} 
The zero profit condition for tradables is standard and, since the world rate of interest is fixed, $\hat{r}=0$. However, the zero profit conditions for nontradables includes the impact of an increasing $\psi$ reflecting any relaxation of the labour market restriction. Both zero profit conditions are solved to obtain an expression for the proportional change in the real exchange rate, $\hat{p}$, as a function of rates of return and cost shares $\mu_{i j}, i \in\{K, L\}, j \in\{T, N\}$,

$$
\begin{gathered}
\hat{A}_{T}=\mu_{L T} \hat{w}+\mu_{K T} \hat{r} \\
\hat{A}_{N}+\hat{p}=\mu_{L N}(\hat{w}+\hat{\psi})+\mu_{K N} \hat{r} \\
\rightarrow \quad \hat{p}=\mu_{L N}\left[\frac{\hat{A}_{T}}{\mu_{L T}}+\hat{\psi}\right]-\hat{A}_{N}, \mu_{L N}=\frac{\psi w L_{N}}{p Y_{N}} .
\end{gathered}
$$

The zero profit conditions in (19) demonstrate that the departure of labour from nontradables $(\hat{\psi}>0)$ and enhanced productivity in tradables $\left(\hat{A}_{T}>0 \rightarrow \hat{w}>0\right)$ both impact on the zero profit condition for nontradables by raising the payments to labour. The latter also affects the zero profit condition for tradables. Solved together, the real exchange rate appreciation $\hat{p}$ is qualitatively similar for both shocks.

Economically, the Balassa-Samuelson effect $\left(\hat{A}_{T}>0 \rightarrow \hat{w}>0\right)$ operates by lifting wages in the traded sector, which leads, for a given $\psi$, to higher wages in nontradables. Clearly, this raises unit costs in nontradables and, from the zero profit condition there, it is apparent that the price of nontradables - the real exchange rate - must rise. Conversely, the RERA $(\hat{\psi}>0)$ is set in train by workers leaving the nontradables sector. But the solution for $k_{T}$ is given by (15), and so it follows that labour arriving in the urban tradables sector is combined in production with mobile capital coming from overseas, to keep $k_{T}$ fixed. Therefore, the mathematical similarities between Balassa-Samuelson and RERA in (19) mirror the visual similarities between the left and right panels of Figure 1.

The size of the intra-economy labour movement, and not just the relative price of nontradables, is of considerable importance for economic policy in developing 
countries. Whilst acknowledging the elegance of the supply side analysis that gives us (19), we need to specify demand to obtain the labour allocations in each sector. The system (15)- (18) delivers $k_{N}$ and $k_{T}$. However, since capital is available elastically from the rest of the world, two equilibrium values of $k_{N}$ and $k_{T}$ are consistent with any amount of capital and labour, in those specified ratios. Thus the size of the economy is indeterminate without considering both a labour constraint and demand. Mathematically speaking, we require two extra equations. One is the economy labour constraint, which we normalize to unity,

$$
L_{N}+L_{T}=1 .
$$

The other is the solution for non-traded production $Y_{N}$ arising from utility maximization. Consumption of tradables and nontradables are denoted $C_{T}$ and $C_{N}$ respectively and all income is wage income, since capital is owned overseas. Suppose utility is homogenous of degree one, hence, each of the partial derivatives of utility $U_{C_{N}}$ and $U_{C_{T}}$ is a function of the relative price,

$$
\max _{C_{N}, C_{T}} U\left(C_{N}, C_{T}\right) \text { s.t. } w L_{T}+\psi w L_{N}=p C_{N}+C_{T}
$$

$\rightarrow$

$$
\begin{aligned}
L & =U\left(C_{N}, C_{T}\right)+\Pi\left[w L_{T}+\psi w L_{N}-\left(p C_{N}+C_{T}\right)\right], \\
U_{C_{N}} & =p \Pi \\
U_{C_{T}} & =\Pi
\end{aligned}
$$

$$
p=\frac{U_{C_{N}}}{U_{C_{T}}} \rightarrow \frac{C_{T}}{C_{N}}=\omega(p)
$$

As is often the case, linear homogeneity in both production and utility lends itself to elegant solutions. The key step is to define the share of nontradables consumption in total consumption, $S_{N}^{C}$,

$$
w-w L_{N}(1-\psi)=p C_{N}+C_{T}
$$




$$
S_{N}^{C}=\frac{p C_{N}}{w-w L_{N}(1-\psi)} .
$$

Then, recalling the definition of $\mu_{L N}$ in (19), we make the substitution of $Y_{N}$ for $C_{N}$ in (23), and rearrange to have,

$$
L_{N}=\frac{\mu_{L N} S_{N}^{C}}{(1-\psi) \mu_{L N} S_{N}^{C}+\psi} .
$$

Equation (24) can be used to bolster our earlier claim that we could have cast our restriction of labour in terms of $L_{N}$ rather than $\psi$. First, we note that when $\psi=1$ (complete labour mobility) the solution from (24), namely $\mu_{L N} S_{N}^{C}$, is optimal, and we denote this as $L_{N}^{*}$. When this is placed back into the formula for $L_{N}$, and with $L_{T}=1-L_{N}$ we can solve for $\psi$. Thus, given any discount on the wage in the nontradables sector we can write down, in a straightforwardly way, the restriction in the quantity of labour that would deliver that discount. That is,

$$
L_{N}=\frac{L_{N}^{*}}{(1-\psi) L_{N}^{*}+\psi} \rightarrow \psi=\frac{L_{T} / L_{N}}{L_{T}^{*} / L_{N}^{*}}
$$

We now work out the proportional change in (24), by including an explicit CES elasticity of substitution between nontradables capital and labour, denoted $\theta_{N}^{p}$, and a CES elasticity of substitution between nontradable and tradable consumption, denoted $\sigma^{c}$. For simplicity, we ignore productivity changes in nontradables. The equality between $C_{N}$ and $Y_{N}$ allows us to write out proportional changes in $C_{N}$ based on (14), and then to define the relevant elasticities.

$$
\begin{aligned}
\hat{C}_{N} & =\mu_{L N} \hat{L}_{N}+\mu_{K N} \hat{K}_{N}+\hat{A}_{N}, \\
\hat{C}_{N}-\hat{C}_{T} & =-\sigma^{c} \hat{p} \\
\hat{L}_{N}-\hat{K}_{N} & =-\theta_{N}^{p}(\hat{w}+\hat{\psi})
\end{aligned}
$$

We now define a number of key ratios. Let $Y$ denote total labour income, which is also total consumption in this model, i.e., $Y=w L_{T}+\psi w L_{N}=p C_{N}+C_{T}$. Then the share of labor/consumption of sector $j$ in the total income/consumption, 
$S_{j}^{i}, i=\{Y, C\}, j=\{T, N\}$, can be expressed as,

$$
\begin{aligned}
& S_{T}^{Y}=\frac{w L_{T}}{Y}, S_{N}^{Y}=1-S_{T}^{Y}, \\
& S_{T}^{C}=\frac{C_{T}}{Y}, S_{N}^{C}=1-S_{T}^{C} .
\end{aligned}
$$

Furthermore, based on (14)-(20), we can rewrite them in proportional changes,

$$
\begin{aligned}
0 & =\mu_{L T} \hat{w}-\hat{A}_{T} \\
\hat{p} & =\mu_{L N}(\hat{w}+\hat{\psi})-\hat{A}_{N} \\
0 & =L_{N} \hat{L}_{N}+L_{T} \hat{L}_{T} \\
\hat{Y} & =\left(\hat{w}+\hat{L}_{T}\right) S_{T}^{Y}+\left(\hat{w}+\hat{L}_{N}+\hat{\psi}\right) S_{N}^{Y}=S_{T}^{C} \hat{C}_{T}+S_{N}^{C}\left(\hat{p}+\hat{C}_{N}\right)
\end{aligned}
$$

Equations (26) to (28) can be combined to give,

$$
\hat{L}_{N}=\hat{C}_{T}-\sigma^{c} \hat{p}-\mu_{K N} \theta_{N}^{p}(\hat{w}+\hat{\psi})
$$

We now eliminate $\hat{C}_{T}$ using (34) and (35) to have,

$$
\hat{L}_{N}=\frac{(\hat{w}+\hat{\psi})\left[\mu_{K N}\left(1-\theta_{N}^{p}\right)+\mu_{L N} S_{T}^{C}\left(1-\sigma^{c}\right)\right]+\hat{\psi}\left(S_{N}^{Y}-1\right)}{1+S_{N}^{Y}(1-\psi) / \psi}
$$

Equation (36) tells us that for the "Cobb-Douglas" benchmark case (as in Section $2, \theta_{N}^{p}=\sigma^{c}=1$ ), a tradables productivity increase, which according to the zero profit condition in tradables in (19) is equivalent to a wage increase, leaves labour allocations unchanged. In that case the impact of changes in $w$ on $L_{N}$ is eliminated in the numerator of (36). As wages rise across the economy (we assume a given $\psi$ ) the price of nontradables rise in a classic Balassa-Samuelson fashion. The price rise leads to a consumption substitution away from nontradables, reducing the demand for labour in that sector. However, the improvement in tradables productivity means that not as much labour is needed for production in that sector. According to (36), the two effects exactly offset each other when there are unitary elasticites and equilibrium labour is unchanged.

Contrariwise, the removal of the wage discount (a higher $\psi$ for given $w$ ) means 
the economy becomes more efficient and the demand for both goods rise. A RERA occurs and consumers substitute away from nontradables. But unlike the previous case there is no increase in productivity in tradables, so the extra demand for them requires extra labour in that sector. For unitary elasticities, the only remaining expression in the numerator of (36) to multiply the increase in the wage discount, $S_{N}^{Y}-1$, is always negative, and so labour used in the production of nontradables must fall.

With a higher than unity capital labour elasticity of substitution in nontradables, a Balassa-Samuelson $(\hat{w}>0)$ or Rural-led $(\hat{\psi}>0)$ appreciation leads to a greater labour loss in nontradables, ceteris paribus. Given a fixed price of capital, the price of labour in nontradables production represents a relative price shift against the use of labour and this more than offsets any productivity induced labour savings in tradables. The same is true for a higher than unity consumption elasticity. As the Balassa Samuelson or Rural-led appreciation occurs, there is a fall in the demand for nontradables. A larger elasticity means a greater shift, and less labour is needed in the sector.

The claim of Figure 1 and equation (19) is that the appreciation associated with a movement of labour out of nontradables and into tradables is qualitatively similar whether it caused by the relaxing of an exogenous restriction, or by an improvement in productivity in tradables. Thus what we have called a Ruralled appreciation, which resonates with the Lewisian tradition in Development Economics if farm output is nontradable, is very similar to a Balassa-Samuelson effect. Though the latter does not need to map the urban-rural dichotomy onto the traded-nontraded dichotomy, we have argued earlier that this is in fact a realistic mapping for some developing countries. 